\title{
THE GENETIC ASSESSMENT OF LOOKED AFTER CHILDREN: \\ Common Reasons for Referral and Recent Advances
}

\section{AFFILIATIONS}

Michael J Parker ${ }^{1}$, Katherine Teasdale ${ }^{2}$, Michael J Parker ${ }^{3}$

${ }^{1}$ Sheffield Clinical Genetics Service

Sheffield Children's Hospital NHS Foundation Trust

Western Bank

Sheffield S10 2TH

michael.parker@sch.nhs.uk

${ }^{2}$ Looked After and Adoptive Children's Health Team

Centenary House

55 Albert Terrace Road

Sheffield S6 3BR

${ }^{3}$ The Ethox Centre

Nuffield Department of Population Health

University of Oxford

Old Road Campus

Oxford OX3 7LF

\section{KEYWORDS}

Looked After Children

Adoption

Genetics

Intellectual Disability

Genetic Testing in Children

Fetal Alcohol Syndrome 
1. Looked After Children are likely to have greater health needs than their peers. For any given child, there are often multiple contributory factors, environmental and genetic.

2. The role of potential genetic factors contributing to a Looked After Child's problems needs to be recognised, but there also needs to be an awareness of the purpose, principles and limitations of a genetic assessment.

3. Current genetic testing will often not produce definitive, clear-cut results. Decisions about testing, and interpretation of results, must therefore be considered in a clinical, familial and social context.

4. It may be appropriate to revisit a child's genetic assessment at some point in the future, as our knowledge and available technology will continue to improve, even if gaps in an individual's history remain.

5. There are significant ethical considerations in predictive and carrier genetic testing of children generally. Looked After Children should be afforded the same protections.

6. Diagnostic criteria exist for Fetal Alcohol Syndrome (FAS) and should be applied. Differential diagnoses and other factors contributing to a child's problems should also be fully considered.

7. Information-sharing and communication are essential to optimise assessments for Looked After Children. It is important to be clear about the questions being asked and the purpose for which the answers will be used.

8. The child's best interests must ultimately remain of paramount importance.

\section{BACKGROUND}

Approximately 93,000 children in the United Kingdom are Looked After, meaning that they are in the care of the local authority, either voluntarily or following a court order.[1] They are some of the most vulnerable children in our society; the majority have a history of abuse and neglect,[1-3] which may include poor parenting and a chaotic lifestyle prior to entering care. Parental health difficulties, including physical and mental health problems, intellectual disability and alcohol or substance misuse are frequently identified. 
Looked After Children are likely to have greater health needs than their peers.[1-3] They may have experienced multiple placements, changes of professionals and separation from their birth families. These factors together can impact on how their medical needs are understood and met. Knowledge of personal and family health information may be crucial to understanding a child's present or likely future health needs, but this may be lost, misunderstood, or withheld by parents in conflict with professionals. The statutory Initial Health Assessment,[3] with generation of a health plan and regular reviews, is a crucial opportunity to gather and analyse the implications of available health information.

For some Looked After Children, adoption is the agreed plan to achieve permanency. Prospective adopters should receive comprehensive information on the child's health following assessment by a Medical Advisor, including the implications of family health issues, or gaps in knowledge. Birth parents are asked to give specific consent for their health information to be obtained by the Medical Advisor, for the benefit of their child, and many are able to do this. However, some cannot be engaged in giving information, or it may not be accessible, e.g. if the paternity of the child cannot be established.

\section{CLINICAL GENETIC ASSESSMENT}

Genetic assessment usually follows the traditional model of history, examination and investigation, so that genetic testing is only part of an assessment. A paediatric genetic history usually has a special emphasis on pregnancy, and a three-generation family history. The examination should be top-to-toe with attention to features suggestive of an underlying syndrome, often referred to as dysmorphology. Clinical photographs are sometimes taken, with the consent of whoever has parental responsibility, to enable further consideration of a child and discussion with colleagues.

Ideally, a child would be seen with their birth parents, to obtain a first-hand medical history and to put a child's problems and appearance into a familial context. If birth parent(s) cannot be present, as much medical and family history as possible should be provided, including (ideally) photographs of birth parents. If a child has a Social Worker, their presence is often invaluable. If this too is not possible, the appropriate information and written consents (for genetic testing and clinical photography as indicated) should be sought in advance of the clinic.

When assessing Looked After Children, there may be conflict between available information and confidentiality issues, especially if paternity is uncertain and/or birth parents are uncooperative. However, without birth parents, comprehensive past medical history and family history, the genetic assessment will be limited, so there may remain uncertainty about the genetic contribution to a child's problems. 
There are three main situations when a Clinical Geneticist may be involved in the assessment of a Looked After Child [See Box 2]. When receiving such a referral, it is important to establish: 1 . what is the question; 2 . who is asking it; and 3 . for what purpose? When there are ongoing Care Proceedings, specific instructions and consents may need to be sought from the Court, prior to seeing the child. As with any other child, the best interests of a Looked After Child must remain of paramount importance.

\section{Box 2: Main reasons Clinical Geneticist asked to see Looked After Child[4]}

1. The child has a particular problem (diagnostic genetic testing).

2. The child is fine, but the family history raises concern (carrier and predictive genetic testing).

3. There is a history of drugs/infections in pregnancy (most commonly suspected Fetal Alcohol Syndrome).

\section{DIAGNOSTIC GENETIC TESTING}

Genetic testing can be divided into diagnostic, carrier or predictive. Diagnostic testing applies when an individual has a health problem, physical and/or developmental, and a genetic test result may make or confirm the diagnosis. This may subsequently enable cascade screening throughout a family.

For many years, diagnostic genetic testing, for apparently non-syndromal or nonspecific intellectual disability, was limited to a G-banded karyotype screen and a Fragile-X Syndrome test. Standard G-banded karyotyping has a pick-up rate of around 3\%.[5] However, in the last decade, Microarray testing has been increasingly incorporated into standard clinical practice. This is essentially a higher-resolution molecular karyotype and enables the detection of sub-microscopic imbalances (deletions or duplications), also known as Copy Number Variants (CNV's). The diagnostic pick-up rate for Microarray screening is approximately $10-15 \%$.[6]

Next Generation Sequencing (NGS) technology is now enabling the introduction of specialist gene panels and Whole Exome (WES) and even Whole Genome Screening (WGS), to screen for mutations within large numbers of genes (not detectable by Microarrays). This is predicted to increase the diagnostic pick-up rate to approximately $27 \% .[7]$

This obviously still leaves a significant proportion of children for whom currentlyavailable genetic testing fails to identify a definitive genetic cause for their problems. Yet there seems to be widely-held belief that genetic testing can test for everything genetic and that results are always clear-cut. In reality, they can: 1. find nothing; 2 . find something unequivocally significant; or 3. report a variant of uncertain significance (VUS's). 
When requesting a genetic test, the anticipation is that this will identify a welldescribed syndrome, with an established literature. However, with advances in genetic testing, more often novel and/or rare variants are identified. Family studies are often crucial to enable interpretation of the significance of variants. For instance, if a variant is present in a parent with similar problems, this increases the likelihood that it is a genuine aetiological factor. However, if present in a parent without similar problems, it could be a benign, familial variant (or reflect variable expression or reduced penetrance within a family). As the body of knowledge improves about relatively-common genetic variants, more-and-more VUS's will be re-classified as either benign or pathological.[8,9]

For example, one of the more commonly-found CNV's in clinical practice is the 15q11.2 BP1-2 Microdeletion. This is generally believed to be enriched in populations with learning difficulties.[10] However, it has a low penetrance and an extremely non-specific and variable spectrum of associated features, such that many now argue it is not a recognisable syndrome and probably not accountable (solely at least) for the problems of any given child.[11,12] Furthermore, this has been used as an example of genetic testing being potentially misleading in the assessment of a Looked After Child.[13] Similar consideration should also be applied to other commonly-found, low penetrance CNV's.[5,14]

As well as VUS's, as with any screening test, there is a potential for Secondary or Incidental Findings (IF's). These are known or suspected pathogenic variants that are not likely to be the cause of an individual's presenting problems. For example, a child with learning difficulties being found to have a pathogenic mutation in an adult cancer gene, such as BRCA1. There is currently much debate about if and how VUS's and IF's should be reported.[15-17]

It is important therefore to know what a test will report, and what it will not, and this should be made clear in the consent process. There are therefore considerable educational implications, for training healthcare professionals about newer genetic technologies, especially as these are likely to be employed more-and-more as first-line investigations in mainstream Paediatrics and other specialties.[18,19]

More comprehensive/advanced testing will be available in the future, our understanding of genetic mechanisms will advance and, perhaps most importantly, our ability to interpret such results in the context of a given individual's problems will continue to improve. Therefore, children should ideally continue to be re-assessed, especially when the potential genetic contribution to their problems is currently unclear. 


\section{CARRIER \& PREDICTIVE GENETIC TESTING IN LOOKED AFTER CHILDREN}

Carrier genetic testing is a term used, in the context of recessive or X-linked conditions, where there are usually no direct health implications for the individual concerned, but the test is being used to inform an individual's future reproductive decisions. Predictive testing is a term used, often in the context of autosomal dominant conditions, usually (although not always) with an adult-onset. Until recently, with the advent of Direct-to-Consumer (DTC) genetic testing (see below), carrier and predictive testing have largely been limited to conditions for which an individual has a family history.

In recent years, there has been a general consensus that genetic testing should not usually be performed in children unless it has a direct health implication for that individual in childhood. Doing so takes away their autonomy to decide for themselves if and when they want such information in the future. There is a potential for adverse psychological effects, and discrimination, of having such information, unsolicited and too young. This position is supported by National, European and International Policy Statements, some more strongly than others, so is known as the Consensus Argument.[20-25] The main ethical argument called upon to justify this position is that, where there is no health benefit in childhood, genetic testing in childhood removes the child's opportunity to make their own decision about genetic testing, as a mature young person or adult.

However, where a child is being considered for adoption, it could be argued that the best interest of the child might be achieved through testing, even where there is no immediate health benefit. Two arguments might be said to be particularly relevant here. Firstly, in order to support successful adoption, it is good practice to make as much information as possible available to potential adoptive parents, and genetic testing should not be treated any differently in this regard.[26-29] Secondly, and relatedly, is the Matching Argument. This asserts that genetic testing is in the child's best interests, where it may have the potential to make it easier to match a child to the most appropriate family, thereby improving the chances of a successful placement. An obvious counterargument here would be that, whilst it would benefit children with good news results, those with adverse genetic test results will be potentially even harder to place and therefore further disadvantaged. However, where placement is proving extremely difficult to achieve without testing, and it is believed that a placement would be in the child's best interest, this argument is likely to be weaker.

Direct-to-Consumer (DTC) genetic testing, as its name implies, bypasses professional pre-test counselling and post-test results interpretation. It is marketed, and therefore accessed, for various reasons including to: investigate ancestry/ethnicity; estimate personal disease risks; and individually tailor drug treatments. However, such tests have variable coverage, validity and therefore clinical utility. There is a general consensus amongst professional groups that DTC genetic testing is not recommended, especially for children who are unable to consent.[30] However, almost by definition, DTC genetic testing is not subject to such constraints/ recommendations. Looked After Children may be subject to DTC genetic testing if adoptive patients seek to fill in gaps in the information they have on their adoptive child.[31] 
With the recent introduction of genomic testing, more-and-more genetic information is potentially becoming available, although this is not always easy to interpret (see above). There would seem to be an increasing shift within society for a greater degree of access to such information, regardless of what an individual may or may not do with it.[32] There is a potential for genomic testing, both clinical and DTC, to be increasingly used to learn more about the genetic background and potential future of children being adopted.

There is likely to be ongoing debate about testing children generally, which will no doubt impact on Looked After Children, especially if the Matching Argument gathers momentum. However, whatever the merits of these arguments at the level of principle, as summarised in Box 3, the key criterion in any decision should of course be the best interest of the child. In practice, this will require the making of (often difficult) judgements in individual cases, rather than the adoption of a generallyapplicable policy on testing.

Box 3: Arguments For \& Against Carrier \& Predictive Genetic Testing in Looked After Children

\begin{tabular}{|c|c|c|}
\hline For: & 1. & $\begin{array}{l}\text { Making as much information as possible available to inform future } \\
\text { clinical and/or social care. } \\
\text { May improve matching/placements. }\end{array}$ \\
\hline Against: & $\begin{array}{l}1 . \\
2 . \\
3 . \\
4 .\end{array}$ & $\begin{array}{l}\text { Removes child's autonomy to make own choice, about having such } \\
\text { information, as a mature young person or adult. } \\
\text { Potential adverse psycho-social effects. } \\
\text { Potential for various forms of discrimination, such as social, } \\
\text { employment and/or insurance. } \\
\text { May make some children more difficult to place. }\end{array}$ \\
\hline
\end{tabular}

\section{FETAL ALCOHOL SYNDROME (FAS) AND OTHER EMBRYOPATHIES}

Embryopathies would seem to have a largely environmental aetiology. However, such children may have dysmorphic features, the assessment of which is traditionally the domain of Clinical Geneticists. Moreover, the differential diagnoses of such conditions are often more clearly genetic ones (see below). Also, there may be a genetic contribution to why a mother may have been taking a particular drug, e.g. a familial predisposition to an addictive personality or a genetic cause for her epilepsy.

Fetal Alcohol Syndrome (FAS) is the most common embryopathy for which a Looked After Child may be referred to a Clinical Geneticist.[33] However, other embryopathies exist, for illicit and prescribed drugs. Anti-convulsants are an important group in the latter category. Illicit drug abuse may involve more than one substance, including alcohol, so compound phenotypes also have to be considered. 
There may be maternal denial or otherwise a paucity of information about exactly what a mother may have been taking in pregnancy. However, every effort should be made to seek objective evidence of alcohol or other drug use, by looking at primary sources, such as maternity notes and Social Services records. Antenatal alcohol exposure should not be assumed on hearsay alone. This potential pitfall may result in a child not being investigated fully for other aetiologies and being prematurelylabelled with an incorrect diagnosis, which can subsequently be difficult to remove.

There is a hierarchy of diagnoses in the FAS spectrum, for which diagnostic criteria exist and should be applied, as with any condition.[34] To meet most diagnostic criteria for full-blown FAS, a child should have documented evidence of maternal alcohol exposure, intellectual disability, growth restriction and the three dysmorphic features of: smooth philtrum, thin vermilion border (upper lip) and short palpebral fissures. However, these dysmorphic features are non-specific and other conditions can mimic FAS. Notable genetic differential diagnoses of FAS include the 22q11 Microdeletion (DiGeorge or Velocardiofacial), Williams, Cornelia-de Lange and Floating-Harbor Syndromes.[33,35]

We would therefore argue that when FAS (or any other embryopathy) is being considered in any given child, they should have a formal dysmorphology assessment, with a low threshold for a baseline Microarray analysis. FAS is also seldom a pure condition, meaning that fetal alcohol exposure may be only one of several contributory, deleterious factors (genetic or environmental) potentially contributing to the problems of a particular child.

\section{SUMMARY}

Looked After Children are recognised as generally having greater health needs than their peers. There are numerous potential causes, environmental and genetic, and the aetiology is often multi-factorial. Assessments, especially Clinical Genetic ones, may be limited if the information available is incomplete or not shared.

There have been some exciting recent advances in diagnostic genetic testing and more are on the horizon. However, we are currently only able to make a genetic diagnosis in less than half of patients, even when both parents are available for comparative testing. There may, therefore, remain an inevitable degree of residual uncertainty about the genetic contribution to a particular child's problems.

There are increasing societal pressures for genetic information to be made available to individuals in general. However, there are significant considerations in carrier/predictive testing in children and we would maintain that Looked After Children should not be treated differently to other children in this regard, unless there is a compelling "best interest" justification for so doing.

Diagnostic criteria exist for FAS and other embryopathies and should be applied. Such should be considered as diagnoses of exclusion, so a child should not be prematurely-labelled with these conditions, without fully assessing for the contribution of other factors, genetic or otherwise. 
Finally, although this review aims to summarise some of the issues we currently believe to be important at the interface between Clinical Genetics and the healthcare of Looked After Children, individual issues/areas are undoubtedly reviewed more comprehensively elsewhere. Moreover, this field will continue to evolve with advances in genetic testing and knowledge, as well as inevitable changes in the societal and political landscape of the day.

\section{ACKNOWLEDGMENTS}

We would like to thank Dr Meena Balasubramanian and Dr Lorraine Pearson for their comments on drafts of this paper. Finally, MJP (Sheffield) would like to dedicate this paper to his late father, Mr Vernon Parker. 


\section{REFERENCES}

1. Children in Care Statistics. 2014 Mar 31. https://www.nspcc.org.uk/preventingabuse/child-protection-system/children-in-care/statistics/ [Accessed 8/12/2015.]

2. Bazalgette L, Rahilly T, Trevelyan G. Achieving emotional wellbeing for looked after children: a whole system approach. 2015. London: NSPCC.

3. Promoting the health and well-being of looked-after children. Statutory guidance for local authorities, clinical commissioning groups and NHS England.

Department for Education and Department of Health; 2015 17/03/2015.

4. Hughes H. Clinical genetics in adoption. Adoption \& Fostering 1990;14(3):54-56.

5. Watson CT, Tomas MB, Sharp AJ, et al. The genetics of microdeletion and microduplication Syndromes: an update. Annu Rev Genomics Hum Genet 2014;15:215-44.

6. Grozeva D, Carss K, Spasic-Boskovic O, et al. Targeted next-generation sequencing analysis of 1,000 individuals with intellectual disability. Hum Mutat 2015;36(12):1197-204.

7. Wright CF, Fitzgerald TW, Jones WD, et al. Genetic diagnosis of developmental disorders in the DDD study: a scalable analysis of genome-wide research data. Lancet 2015;385(9975):1305-14.

8. Coe BP, Witherspoon K, Rosenfeld JA, et al. Refining analyses of copy number variation identifies specific genes associated with developmental delay. Nat Genet 2014;46(10):1063-71.

9. Beaudet AL. Reaching a CNV milestone. Nat Genet 2014;46(10):1046-8.

10. Burnside RD, Pasion R, Mikhail FM, et al. Microdeletion/microduplication of proximal 15q11.2 between BP1 and BP2: a susceptibility region for neurological dysfunction including developmental and language delay. Hum Genet 2011;130(4):517-28.

11. Chaste P, Sanders SJ, Mohan KN, et al. Modest impact on risk for autism spectrum disorder of rare copy number variants at 15q11.2, specifically breakpoints 1 to 2. Autism Res 2014;7(3):355-62.

12. Hashemi B, Bassett A, Chitayat D, et al. Deletion of 15q11.2 (BP1-BP2) region: further evidence for lack of phenotypic specificity in a pediatric population. Am J Med Genet A 2015;167(9):2098-102.

13. Hamilton MJ, Tolmie JL, Joss S, et al. Chromosomal microarray analysis for looked after children: a double-edged sword? Arch Dis Child 2015;100(2):206-7.

14. Rosenfeld JA, Coe BP, Eichler EE, et al. Estimates of penetrance for recurrent pathogenic copy-number variations. Genet Med 2012;15(6):478-81. 
15. Hoge SK, Appelbaum PS. Ethics and neuropsychiatric genetics: a review of major issues. Int J Neuropsychopharmacol 2012;15(10):1547-57.

16. Clarke AJ. Managing the ethical challenges of next-generation sequencing in genomic medicine. Br Med Bull 2014;111(1):17-30.

17. Botkin JR, Belmont JW, Berg JS, et al. Points to consider: ethical, legal, and psychosocial implications of genetic testing in children and adolescents. Am J Hum Genet 2015;97(1):6-21.

18. Miller D, Adam M, Aradhya S, et al. Consensus statement: chromosomal microarray is a first-tier clinical diagnostic test for individuals with developmental disabilities or congenital anomalies. Am J Hum Genet 2010;86(5):749-64.

19. Briggs TA, Harris J, Innes J, et al. The value of microarray-based comparative genomic hybridisation (aCGH) testing in the paediatric clinic. Arch Dis Child 2015;100:728-31.

20. Barnes C. Genetic testing and adoption. Practice note No. 50. London: British Association for Adoption and Fostering; 2006.

21. British Society of Human Genetics (BSHG). Genetic testing of children. Report of a working party of the British Society for Human Genetics, 2010.

22. Borry P, Evers-Kiebooms G, Cornel MC, et al. Genetic testing in asymptomatic minors: background considerations towards ESHG Recommendations. Eur J Med Genet 2009;17(6):711-9.

23. European Society of Human Genetics (ESHG). Genetic testing in asymptomatic minors: recommendations of the European Society of Human Genetics. Eur J Med Genet 2009;17(6):720-1.

24. American Academy of Pediatrics and the American College of Medical Genetics and Genomics. Ethical and policy issues in genetic testing and screening of children. Pediatrics 2013;131(3):620-2.

25. Ross LF, Saal HM, David KL, et al. American Academy of Pediatrics; American College of Medical Genetics and Genomics. Technical report: ethical and policy issues in genetic testing and screening of children. Genet Med 2013;15(3):234-45.

26. Jansen LA, Ross LF. The ethics of preadoption genetic testing. Am J Med Genet A 2001;104(3):214-20.

27. Parker M. Genetic testing in children and young people. Fam Cancer 2010;9(1):15-8.

28. English, R. Genetic testing of children up for adoption. UK Human Rights Blog 2013 Apr 27; http://ukhumanrightsblog.com/2013/04/27/genetic-testing-ofchildren-up-for-adoption/. [Accessed 10/09/2015.] 
29. Leighton KJ. Accepting adoption's uncertainty: the limited ethics of pre-adoption genetic testing. $J$ Bioeth Inq 2014;11(2):245-60.

30. Burton A. Are we ready for direct-to- consumer genetic testing? Lancet Neurol 2015;14(2):138-9.

31. Crouch J, Yu J, Shankar AG, et al. "We don’t know her history, her background”: adoptive parents' perspectives on whole genome sequencing results. $J$ Genet Counsel 2015;24(1):67-77.

32. Middleton A, W. Potential research participants support the return of raw sequence data. J Med Genet 2015;52(8):571-4.

33. Douzgou S, Breen C, Crow YJ, et al. Diagnosing fetal alcohol syndrome: new insights from newer genetic technologies. Arch Dis Child 2012;97(9):812-7.

34. BMA Board of Science. Fetal alcohol spectrum disorders: a guide for healthcare professionals. 2007.

35. Winter RM BM. Winter-Baraitser Dysmorphology Database. London Medical Databases 2015;1.0.35. 